\title{
Overdose of dolutegravir in combination with tenofovir disaproxil fumarate/emtricitabine in suicide attempt in a 21-year old patient
}

\author{
Marcel Lee ${ }^{1 *}$, Florian Eyer ${ }^{1}$, Norbert Felgenhauer ${ }^{1}$, Hartwig HF Klinker ${ }^{2}$ and Christoph D Spinner ${ }^{3^{*}}$
}

\begin{abstract}
A 21 year old MSM patient with newly diagnosed HIV infection was hospitalized in our department after ingestion of an overdose of his antiretroviral therapy (ART) comprising dolutegravir (DTG - Tivicay ${ }^{\circledR}$ ) and tenofovir disaproxil fumarate/emtricitabine (Truvada ${ }^{\oplus}$ ) in suicidal intention. On admission, the patient did not show any clinical signs of intoxication and laboratory findings were unremarkable. After 6 hours of intensive care monitoring, the patient was referred to a psychiatric clinic. 5 days after the day of intoxication, serum creatinine levels increased to high normal values $(1.2 \mathrm{mg} / \mathrm{dl})$. However, levels never exceeded the upper threshold. 8 and 12 weeks later, serum creatinine normalized to levels measured prior to the intoxication. No other adverse events occurred, and the patient does not suffer from permanent impairments.
\end{abstract}

Keywords: HIV, AIDS, Suicide attempt, Dolutegravir, Tenofovir disaproxil fumarate, Emtricitabine, Overdose

\section{Background}

Antiretroviral therapy is employed in HIV patients to achieve durable suppression of HIV replication, thereby controlling HIV RNA, to restore immune function and to reduce morbidity and mortality, to improve quality of life, as well as to limit the likelihood of viral resistance and reduce the risk of viral transmission [1-3]. Dolutegravir (DTG) is a novel second-generation integrase inhibitor and has recently been introduced for use as antiretroviral therapy of HIV infection [4]. Recommended dose for treatment of therapy-naive patients is $50 \mathrm{mg}$ per day. DTG is known to be an inhibitor of the renal transport protein organic cation transporter 2 (OCT2), resulting in a reversible elevation of serum creatinine [5]. Furthermore, inhibition of the OCT2 can result in relevant drug interactions, e.g. dofetilide, metformin, cimetidine, triamterene, and procainamide [6].

\footnotetext{
* Correspondence: Marcel.lee@tum.de; christoph.spinner@tum.de 'Department of Clinical Toxicology, University Hospital Klinikum rechts der Isar, Technische Universität München, Ismaningerstr. 22, Munich 81675, Germany

${ }^{3}$ Department of Medicine II and Interdisciplinary HIV Center (IZAR), University Hospital Klinikum Rechts Der Isar, Technische Universität München, Ismaningerstr. 22, Munich 81675, Germany

Full list of author information is available at the end of the article
}

\section{Case presentation}

We report a 21-year old MSM patient who was admitted to our department on June 2014 following an overdose of antiretroviral medication (ART) in suicidal intention. HIV-infection was diagnosed 3 weeks prior to his admission to our department.

CDC-stage of the HIV infection at primary diagnosis was A1, WHO stage I with a documented CD4-nadir of

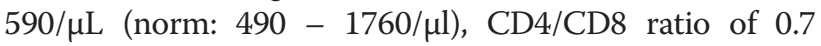
(norm 1.0 - 5.8) and an HIV load of $42.400 \mathrm{cps} / \mathrm{ml}$. HIV diagnostic was performed because of a syphilis stage II infection with a generalized rash, a couple of weeks before. The syphilis infection was treated with doxycycline $200 \mathrm{mg}$ per day for 14 weeks and due to incomplete decrease of VDRL titers followed by intramuscular benzathine penicillin 2.4 million units on day $0,7,14$. With the patient's consent an ART with DTG (Tivicay') and tenofovir disaproxil fumarate/emtricitabine (TDF/ FTC - Truvada ${ }^{\circ}$ ) was initiated immediately.

His medical history includes an allergic bronchial asthma, which is treated with ipratropium bromide and fenoterol hydrobromide. The patient reported on request occasional cocaine consumption (recreational drug abuse).

On day of admission, the patient reports to have taken 15-20 pills of TDF/FTC and the same amount of DTG, 
amounting to a maximum of $4900 \mathrm{mg}$ TDF/ $4000 \mathrm{mg}$ FTC and $1000 \mathrm{mg}$ DTG in suicidal intention. He admitted having combined the ART overdose with an unknown amount of vodka and cocaine. Exact time of ingestion was unclear but most likely within the past 4 hours prior to admission. Physical examination revealed minor airway obstruction; the remaining examination was without pathological findings. The patient did not specify any complaints. He was hospitalized and monitored for 6 hours on our intensive care unit. Within that period of time, no adverse events occurred, no specific therapy was necessary.

Upon admission a serum sample was routinely taken. Blood analysis revealed a minimal TSH-elevation while normal free thyroid hormons were documented (TSH $4.30 \mu \mathrm{IU} / \mathrm{ml}$, fT3 $4.0 \mathrm{pg} / \mathrm{ml}, \mathrm{fT} 41.4 \mathrm{ng} / \mathrm{ml}$ ) (Norm: TSH $0.27-4.2 \mu \mathrm{IU} / \mathrm{ml}$, fT3: $2.00-4.30 \mathrm{pg} / \mathrm{ml}$, fT4: $0.90-$ $1.90 \mathrm{ng} / \mathrm{ml}$ ), which was discussed as latent hypothyroidism formally. The remaining parameters showed no pathological findings. Electrocardiographic analysis showed no pathological findings, especially QTc time was normal. DTG concentration in serum sample was $10,013 \mathrm{ng} / \mathrm{ml}$ (norm: > $500 \mathrm{ng} / \mathrm{ml}$ ). To date, the analyzing lab did not establish upper limits, however the IC90 for DTG is $64 \mathrm{ng} / \mathrm{ml}$ [7], and the mean plasma concentration from 102 samples acquired from 65 patients analyzed in our lab was $2,226 \mathrm{ng} / \mathrm{ml}(+/-1,693 \mathrm{ng} / \mathrm{ml})$. These data justify the conclusion that there was a relevant overdosing in our patient, measured approximately 4 hours after ingestion. Toxicological analysis revealed an ethanol concentration of $0.48 \mathrm{~g} / \mathrm{l}$. Intracellular TDF- and FTC-levels could not be monitored, because no cell fraction sample was stored at time of admission. Creatinine concentration on admission was $0.8 \mathrm{mg} / \mathrm{dl}(70.72 \mu \mathrm{mol} / \mathrm{l})$ (range: $0.5-1.3 \mathrm{mg} / \mathrm{dl}$; $44.2-114.92 \mu \mathrm{mol} / \mathrm{l})$. Five days after ingestion, creatinine concentration increased $50 \%$ to $1.2 \mathrm{mg} / \mathrm{dl}(106.08 \mu \mathrm{mol} / \mathrm{L})$, however, the parameter never exceeded the pathologic threshold. Subsequent analysis of serum creatinine eight weeks later revealed slight reduction to $1.1 \mathrm{mg} / \mathrm{dl}$ (97.24 $\mu \mathrm{mol} / \mathrm{l})$, analysis 12 weeks later revealed further reduction of serum levels to $0.9 \mathrm{mg} / \mathrm{dl}(79.56 \mu \mathrm{mol} / \mathrm{l})$, representing his baseline serum creatinine. (Figure 1) No evidence for any proteinuria or Fanconi syndrome was observed during observation's period.

The patient was discharged after uneventful monitoring from the hospital without any symptoms and TDF/ FTC + DTG ART was continued without any changes. He was followed up in the HIV outpatient center and psychiatric therapy was offered.

\section{Conclusion}

Our case of a 21-year old HIV-patient ingesting an overdose of DTG and TDF/FTC in suicidal intention suggests a broad safety range of the above mentioned HIV

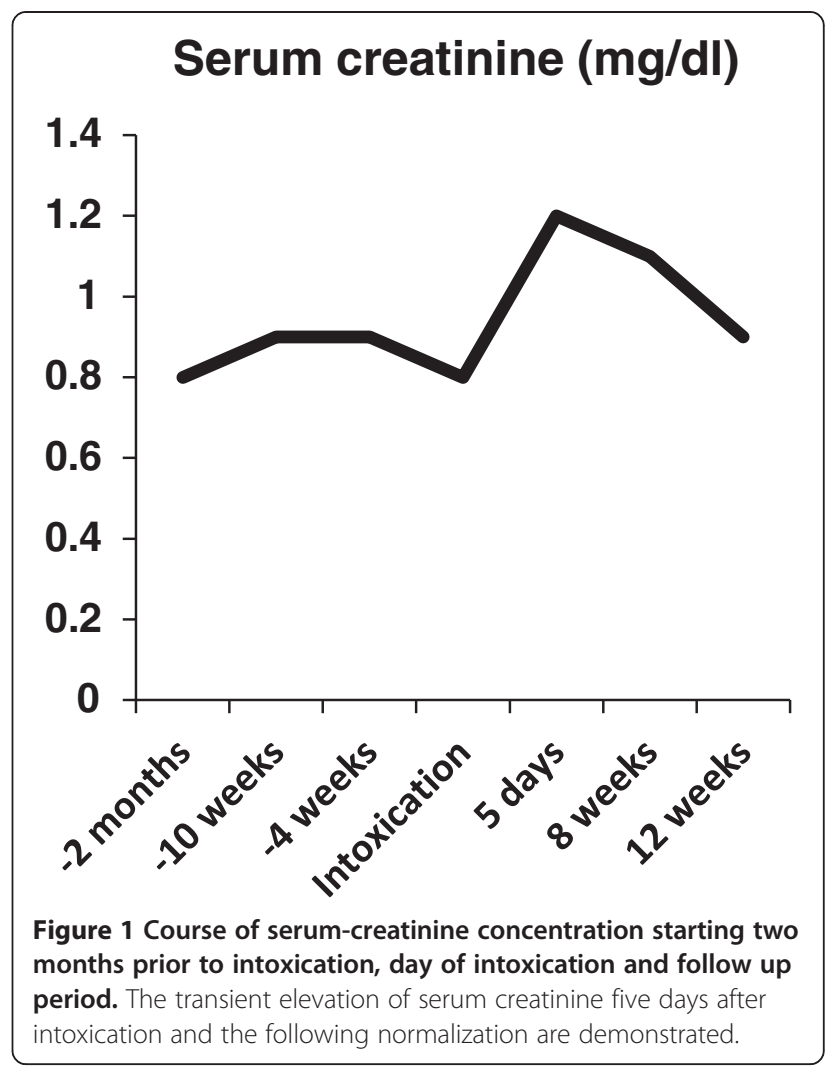

drugs in the overdose setting of an otherwise healthy patient. As has been reported, DTG is a potent inhibitor of the renal transporter OCT2 with creatinine accumulation resulting from that effect $[5,8]$. In combination with the potential nephrotoxic TDF, this could lead to impaired renal function in case of overdose with one or both drugs. To the best of our knowledge, additional effects of TDF overdose or TDF and DTG overdose with possible implications on renal function of both drugs have not been reported so far [9]. However, previous studies demonstrated that the elevation of creatinine following DTG ingestion is not a consequence of reduction in renal blood flow or renal creatinine clearance (i.e. no nephrotoxic effect), but is rather directly attributable to the inhibition of OCT2. This effect was found to be reversible [10].

The clinical course of our patient, showing an increase in creatinine baseline levels of $50 \%$ within the first five days after ingestion, but recovering to previous levels after the acute event, support the current safety data of DTG leading to an intermittent increase in serum creatinine. No permanent impairment in renal function remained in our case.

In conclusion, DTG over dosage does not seem to lead to sustained nephrotoxic effects in our case, which supports the previous study findings of the favorable safety profile of the drug. Further data from routine clinical 
use and safety studies are needed to confirm these findings in case of DTG overdose.

\section{Consent}

Written informed consent was obtained from the patient for the publication of this report and any accompanying images.

\section{Abbreviations}

ART: Antiretroviral therapy; DTG: Dolutegravir; FTC: Emtricitabine; OCT2: Organic cation transporter 2; TDF: Tenofovir disaproxil fumarate.

\section{Competing interests}

Christoph D. Spinner received grants from AbbVie Germany, Boehringer Ingelheim, Bristol-Myers Squibb, Gilead Sciences, Janssen-TMC, Pfizer Germany, ViiV Healthcare. CDS is participating in multi-center studies, which are supported by AbbVie Germany, Sanofi Aventis, Janssen-Cilag and ViiV Healthcare. He received Gilead Sciences grants for research work. HHFK received grants, Board membership fees and lecture fees from AbbVie, Boehringer, Bristol-Myers Squibb, Gilead, Glaxo-SmithKline, Hexal, Janssen-Cilag, MSD, Roche, and ViiV Healthcare. All other authors declare no conflict of interest.

\section{Authors' contributions}

$\mathrm{ML}$ and CDS collected the patient's data, did the database research for references and drafted the manuscript. HK provided the measurement of DTG levels. NF was the attending physician in the ICU, monitoring the patient. FE supervised the draft process. All authors read and approved the final manuscript.

\section{Acknowledgements}

We would like to thank Bettina Haberl for her laboratory help preparing the patient's serum sample. This work was supported by the German Research Foundation (DFG) and the Technische Universität München within the funding programme Open Access Publishing.

\section{Author details}

${ }^{1}$ Department of Clinical Toxicology, University Hospital Klinikum rechts der Isar, Technische Universität München, Ismaningerstr. 22, Munich 81675, Germany. ${ }^{2}$ Department of Medicine II, Division of Infectious Diseases, University Of Wuerzburg Medical Center, Oberduerrbacherstr. 6, Wuerzburg 97080, Germany. ${ }^{3}$ Department of Medicine II and Interdisciplinary HIV Center (IZAR), University Hospital Klinikum Rechts Der Isar, Technische Universität München, Ismaningerstr. 22, Munich 81675, Germany.

Received: 5 November 2014 Accepted: 10 April 2015

Published online: 21 May 2015

\section{References}

1. Doherty M, Ford N, Vitoria M, Weiler G, Hirnschall G. The 2013 WHO guidelines for antiretroviral therapy: evidence-based recommendations to face new epidemic realities. Curr Opin HIV AIDS. 2013;2013(8):528-34.

2. Lee FJ, Amin J, Carr A. Efficacy of initial antiretroviral therapy for HIV-1 infection in adults: a systematic review and meta-analysis of 114 studies with up to 144 weeks' follow-up. PLoS ONE. 2014;9, e97482.

3. Cohen MS, McCauley M, Gamble TR. HIV treatment as prevention and HPTN 052. Curr Opin HIV AIDS. 2012;7:99-105.

4. Osterholzer DA, Goldman M. Dolutegravir: A Next Generation Integrase Inhibitor for Treatment of HIV Infection. Clin Infect Dis. 2014;59(2):265-71.

5. Reese MJ, Savina PM, Generaux GT, Tracey H, Humphreys JE, Kanaoka E, et al. In vitro investigations into the roles of drug transporters and metabolizing enzymes in the disposition and drug interactions of dolutegravir, a HIV integrase inhibitor. Drug Metab Dispos. 2013;41:353-61.

6. Shah BM, Schafer JJ, Desimone JA. Dolutegravir: a new integrase strand transfer inhibitor for the treatment of HIV. Pharmacotherapy. 2014:34:506-20.

7. Cottrell ML, Hadzic T, Kashuba ADM. Clinical pharmacokinetic, pharmacodynamic and drug-interaction profile of the integrase inhibitor dolutegravir. Clin Pharmacokinet. 2013;52:981-94.
8. Lepist E-I, Zhang X, Hao J, Huang J, Kosaka A, Birkus G, et al. Contribution of the organic anion transporter OAT2 to the renal active tubular secretion of creatinine and mechanism for serum creatinine elevations caused by cobicistat. Kidney Int. 2014;86:350-7.

9. Margolis AM, Heverling H, Pham PA, Stolbach A. A review of the toxicity of HIV medications. J Med Toxicol. 2014;10:26-39.

10. Koteff J, Borland J, Chen S, Song I, Peppercorn A, Koshiba T, et al. A phase 1 study to evaluate the effect of dolutegravir on renal function via measurement of iohexol and para-aminohippurate clearance in healthy subjects. Br J Clin Pharmacol. 2013;75:990-6.

\section{Submit your next manuscript to BioMed Central and take full advantage of:}

- Convenient online submission

- Thorough peer review

- No space constraints or color figure charges

- Immediate publication on acceptance

- Inclusion in PubMed, CAS, Scopus and Google Scholar

- Research which is freely available for redistribution 